\title{
A EXPERIÊNCIA DE CUIDAR DO PACIENTE CIRÚRGICO: AS PERCEPÇÕES DOS ALUNOS DE UM CURSO DE GRADUAÇÃO EM ENFERMAGEM*
}

\section{THE EXPERIENCE OF CARE FOR THE SURGICAL PATIENT: THE NURSING STUDENTS' PERCEPTIONS}

\author{
Flávia Tatiana Pedrolo** \\ Sabrina Hannickel** \\ Janaina Zambon de Oliveira** \\ Márcia Maria Fontão Zago***
}

PEDROLO, FT et al. A experiência de cuidar do paciente cirúrgico: as percepções dos alunos de um curso de graduação em enfermagem. Rev Esc Enf USP, v.35, n. 1, p. 35-40, mar. 2001.

\begin{abstract}
RESUMO
Este estudo teve como objetivo apreender as percepções que os alunos de graduação de enfermagem têm do ato de cuidar do paciente cirúrgico. Foi utilizada a metodologia qualitativa e os dados foram coletados por entrevistas semiestruturadas, A análise dos dados identificou as categorias: caracterização do paciente cirúrgico, habilidades necessárias para o cuidar, dificuldades para o cuidar, resultados percebidos quanto à aprendizagem do cuidar. As categorias foram integradas no tema "vencer a cultura do cuidar do paciente cirúrgico", pelo qual apreendemos que a experiência é influenciada pelos valores, conhecimentos e crenças da cultura da enfermagem cirúrgica, encontradas no cotidiano da assistência e na literatura.
\end{abstract}

PAlAVRAS-CHAVE: Percepção. Alunos de enfermagem. Cuidados de enfermagem. Assistência ao paciente.

\begin{abstract}
The purpose of this study was to apprehend the nursing students' perceptions about the experience of caring for the surgical patient. Using the qualitative methodology the authors identified the categories: the characterization of the surgical patient, the skills to care, the difficulties to care and the perceptible outcomes of the learning to care. The categories were integrated into the theme "To win the culture of care of the surgical patient". The results evidence the great cultural influence of values, knowledge and believes of surgical nursing met in the practical context and in the literature.
\end{abstract}

KEYWORDS: Perception, Nursing student. Nursing care. Patient care,

\section{INTRODUÇÃO E JUSTIFICATIVA}

Qualquer que seja o procedimento cirúrgico a que um paciente se submete, este é sempre uma situação de crise para ele e seus familiares. Mesmo em cirurgias de pequeno porte, o paciente e seus familiares se vêem frente a eventos novos e ameaçadores, Os efeitos ou conseqüências de uma cirurgia não se resumem a uma incisão e alteração funcional de um órgão. Implicam inúmeras mudanças no cotidiano da sua vida pessoal, familiar, profissional e social (ZAGO, 1994).
É neste contexto sócio-cultural que os enfermeiros cirúrgicos encontram-se inseridos e, da mesma forma, os alunos de graduação em enfermagem. Desde os primeiros meses do curso de graduação, pelas interações com outros alunos, eles vão obtendo informações as mais variadas, que aos poucos constituem uma base de conhecimentos, crenças e valores sócio-culturais sobre o paciente cirúrgico e o campo de atuação do enfermeiro cirúrgico. Desta forma, criam-se expectativas e perspectivas sobre o cuidar do paciente cirúrgico.

\footnotetext{
- Trabalho com subvenção do CNPq, processo n ${ }^{\circ}$ 520604/96-2,

** Aluna do Curso de Graduação em Enfermagem. Escola de Enfermagem de Ribeirão Preto - USP. Bolsistas da FAPESP, CNPq, Coseas.

*** Enfermeirá. Professora Doutora da Escola de Enfermagem de Ribeírão Preto-USP. Orientadora do estudo.
} 
Como bolsistas de iniciação científica integradas aos projetos de pesquisa do Grupo de Apoio e Reabilitação de Pessoas Ostomizadas (GARPO Laringectomizados), da Escola de Enfermagem de Ribeirão Preto - USP, estamos desenvolvendo estudos sobre a reabilitação do paciente cirúrgico oncológico, sob diferentes abordagens teóricas e metodológicas.

Nesta fase inicial de nossas vidas como discentes, muitas questões afloram: Como é cuidar do paciente cirúrgico? Como são as experiências de aprendizagem com esse paciente? Seremos capazes de desenvolver uma pesquisa sob a abordagem metodológica qualitativa? Essas questões perduraram por alguns meses. Buscamos respostas com os colegas que vivenciaram a experiência e percebemos que ela foi muito rica, em diferentes aspectos.

Assim, propusemos a realização deste estudo com as finalidades de inserirmo-nos no desenvolvimento de um estudo sob a abordagem qualitativa e de apreendermos a riqueza das situações vivenciadas por um grupo de alunos que já passaram pela disciplina de Enfermagem Cirúrgica e, portanto, cuidaram do paciente cirúrgico. Desse modo, o objetivo do estudo é "apreender as percepções que os alunos de graduação em enfermagem têm do ato de cuidar do paciente cirúrgico".

\section{O PACIENTE CIRÚRGICO}

O paciente cirúrgico é a pessoa que irá ser submetida a uma cirurgia, eletiva ou de emergência, para o tratamento de uma doença. Desde a internação, o paciente é envolvido por vários fatores que acarretam mudanças em sua vida e na da sua família. Todo paciente cirúrgico sofre algum tipo de reação emocional, explícita ou implícita. Assim, o estresse fisiológico e emocional sempre acompanha o paciente, desde o momento do diagnóstico médico até a alta hospitalar. Não podemos deixar de salientar que, a hospitalização por si só, acarreta uma situação de estresse.

Segundo GOLDENBERG; BEVILACQUA (1984), a cirurgia é o procedimento terapêutico para uma variedade de distúrbios fisiopatológicos que implicam ameaças reais, tais como, risco de vida, perda de órgãos ou parte dos mesmos, de lesões, prejuízos financeiros, postergação de projetos de vida, além do próprio desconforto decorrente da internação (separação da familia, sofrimento, dor, insegurança e outros).

BLACK; MATASSARIN-JACOBS (1996) afirmam que a cirurgia provoca o desequilibrio de todos os sistemas orgânicos e esse estresse pode evidenciar-se psicológica ou fisicamente. Os autores conceituam estresse gomo um termo coletivo, usado para descrever os muitos fatores psicológicos e fisiológicos que causam alterações neuroquímicas no organismo.

O estresse emocional leva ao surgimento da ansiedade que influencia diretamente o funcionamento do organismo. Portanto, a recuperação fisiológica e a reabilitação psicossocial do paciente ficam comprometidas na situação cirúrgica (SMELTZER; BARE, 1998).

Esses aspectos que envolvem o paciente em situação cirúrgica também geram uma série de expectativas e perspectivas para o aluno de enfermagem $\mathrm{e}$ mesmo para o enfermeiro que o assiste. A atenção deve ser constante quanto à detecção de sinais e sintomas de alguma possivel complicação pré ou pós-operatória, às reações emocionais e comportamentais ao ambiente cirúrgico (enfermaria, centro cirúrgico e centro de recuperação), à administração de medicamentos e à implementação de ações de cuidado em geral (curativos, deambulação precoce, jejum, reinicio da dieta, aspiração de traqueostomia e outras).

LUCKMANN; SORENSEN (1996) afirmam que os avanços tecnológicos e a mudança do ambiente cirúrgico contribuíram para a expansão da prática de enfermagem perioperatória. A segurança e o bem-estar do cliente constituem o principal objetivo durante todas as fases da experiência perioperatória.

Assim, os enfermeiros desempenham diferentes papéis e têm várias responsabilidades no cuidado ao paciente cirúrgico, o que contribui para a sua recuperação/reabilitação. Os papéis do enfermeiro incluem ensino, preparo físico e psicológico, avaliação e alta do paciente.

LENARDT (1996) afirma que o paciente cirúrgico é um ser humano, internado em uma unidade cirúrgica hospitalar, que precisa ser conhecido e compreendido, com seus valores culturais e suas necessidades específicas.

Neste contexto, a disciplina de Enfermagem Cirúrgica da Escola de Enfermagem de Ribeirão Preto - USP é oferecida no $6^{\circ}$ semestre do curso e sua programação compreende conteúdos teórico-práticos relacionados com as atividades dos enfermeiros nos ambientes cirúrgicos e com a assistência ao paciente nos diferentes períodos: pré, trans e pós-operatório. A disciplina possibilita várias oportunidades para os alunos desenvolverem-se como profissionais e estas oportunidades podem ser geradoras de perspectivas, as quais serão integradas ao conhecimento dos alunos, para futuras aplicações como profissionais. São essas perspectivas, os significados desenvolvidos, que queremos apreender e compartilhar. 


\section{METODOLOGIA}

Para o alcance do objetivo proposto, utilizamos a abordagem metodológica qualitativa, segundo LUDKE; ANDRÉ (1986). Segundo as autoras, a abordagem metodológica qualitativa possibilita compreender a complexidade das experiências, os seus significados. Os dados qualitativos permitem apreender $\mathrm{o}$ aspecto multi-dimensional dos fenômenos, capturando os diferentes significados das experiências no ambiente investigado, de modo a auxiliar a compreensão das relações entre os indivíduos, seu contexto e suas ações. Neste sentido, o fenômeno que nós pesquisadores objetivamos apreender refere-se às percepções que os alunos de enfermagem têm do ato de cuidar do paciente cirúrgico.

A amostra intencional selecionada para o estudo consistiu de 9 alunos do curso de graduação da Escola de Enfermagem de Ribeirão Preto - USP. Destes alunos, 8 eram do $6^{\circ}$ semestre e 1 era do $7^{\circ}$ semestre, tendo todos já concluído a disciplina de Enfermagem Cirúrgica; 7 eram do sexo feminino e 2 do sexo masculino. A idade média dos alunos era de 20 anos.

O estudo foi submetido à apreciação do Comitê de Ética em Pesquisa da instituição. Todos os informantes tiveram informações sobre o objetivo e a metodologia do estudo. Foram considerados os aspectos éticos na pesquisa: aceitação dos informantes em participar do estudo, permissão para gravar a entrevista, manutenção do anonimato dos informantes.

A coleta de dados ocorreu na própria instituição de ensino, sendo realizada pela entrevista semiestruturada, pelas seguintes questões norteadoras:

- O que você achou de cuidar do paciente cirúrgico?

- Conte uma situação que aconteceu com você quando estava com o paciente.

As entrevistas foram realizadas em horários disponiveis pelos informantes e tiveram duração média de vinte minutos; foram gravadas e, posteriormente, transcritas na integra.

Seguindo as diretrizes do referencial metodológico utilizado, a análise dos dados foi desenvolvida pelas seguintes etapas: organização dos dados, leitura flutuante dos mesmos, delimitação dos conteúdos dos dados em códigos ou categorias empíricas, novas leituras em busca de inferências de significados, identificação de categorias analíticas. Esta última etapa consiste na interpretação dos dados quando estes são reagrupados e transformados os seus sentidos, em busca dos significados. Essa é a etapa de maior abstração, no processo de interpretação.

\section{A APREENSÃO DAS PERCEPÇÕES}

Tendo como base o objetivo e as questões norteadoras do estudo, passamos à interpretação e discussão das informações obtidas. As categorias analiticas serão apresentadas a seguir com as seguintes denominações: caracterização do paciente cirúrgico, habilidades necessárias para - cuidar, dificuldades para o cuidar e resultados percebidos quanto à aprendizagem do cuidar.

\subsection{Caracterização do paciente cirúrgico}

Nas falas dos alunos, os conteúdos relacionados com a caracterização do paciente cirúrgico emergem com grande freqüência, denotando a valorização desta percepção:

"..é um paciente que tem alta
complexidade..."

"Esse paciente não é apenas uma incisão cirúrgica mas, sim, uma pessoa que deve ser sempre avaliada. Apresenta dor, passa por uma situação de estresse, muita ansiedade em relação ao seu prognóstico e a familia."

"O paciente cirúrgico tem um perfil diferente da maioria dos pacientes do hospital. $E$ mais esclarecido, mais orientado."

"Ele fica pouco tempo no hospital. Ele não fica com "hospitalite"'".

"É um paciente diferenciado, ele vai submeter-se a uma cirurgia, vai enfrentar um procedimento que envolve medo e ansiedade, uma série de alterações metabólicas no organismo."

O modo como os alunos categorizam o paciente denota uma apreensão que acreditamos ser histórico na Enfermagem Cirúrgica. Há muitos anos, desde as suas primeiras publicações, os livros textos de Enfermagem Médico-Cirúrgica, largamente utilizados no ensino, trazem esta conotação. Assim, com o passar do tempo, a classificação do paciente cirúrgico como sendo de "alta complexidade" retrata um simbolismo que se perpetua até os dias de hoje na cultura da Enfermagem Cirúrgica e também entre os alunos. Entretanto, nesta categorização emerge o reconhecimento de alguns aspectos do cuidar do paciente, como a realização do curativo, a troca de bolsa de colostomia, a aspiração da traqueostomia, devido a sua condição aguda de saúde.

Por outro lado, consideramos que esses aspectos podem ser resultantes das experiências individuais dos alunos. 


\subsection{Habilidades necessárias para o cuidar}

Como todo ser humano em formação, os alunos frente a uma nova situação de aprendizagem, influenciados pela caracterização dos pacientes com os quais irão lidar, comparando os pacientes submetidos a diferentes tipos de tratamentos cirúrgicos, e somatizando as suas experiências, focalizam diferentes habilidades para o cuidar do pacientes cirúrgico:

"...você tem que ter uma visão geral deles: condições de pressão, sinais vitais, condição da ferida. Você tem que estar atento... é muito interessante porque você não fica preso só na ferida..."

"É um olhar diferente que ai gente está atento..."

"São muitas pequenas coisas! Na Recuperação... é verificar sinais vitais, é papa de hemaceas, muita coisa rápida, uma em cima da outra!"

"...Você acaba se identificando com ele e quer dar o melhor cuidado do mundo!"

"Como ele não fica muito tempo internado, é tudo muito rápido. Eu percebi a importância de fazer uma boa anotação, avaliação diária. E não é só isso. O paciente cirúrgico requer outras coisas: ensino, orientação de todas as dúvidas $e$ alivio da dor..."

"..priorizar, planejamento..."

O modo como os alunos referem-se verbalmente ao cuidar do paciente cirúrgico demonstra a motivação pela experiência. Entre as habilidades mais destacadas, citamos a atenção, agilidade, o conhecimento dos procedimentos, a avaliação do paciente, o desenvolvimento do planejamento da assistência. Porém, essas habilidades não são específicas do cuidar do paciente cirúrgico e fazem parte da formação integral do enfermeiro. A experiência, pelo modo como é percebida, pode ressaltar estas necessidades.

\subsection{Dificuldades para o cuidar}

Nesta categoria, as dificuldades dos alunos para o cuidar são destacadas ora pela inexperiência, ora pela falta de segurança característica de todo profissional em formação, pelas características do paciente e pela responsabilidade do seu cuidado, mesmo como aluno. Assim, como toda experiência nova, expectativas são criadas e os medos são expostos:

"..foi a própria dificuldade do paciente. A dificuldade dele se movimentar, a dor que ele sempre refere, dificuldade para se alimentar."
"Realizar procedimentos que eu nunca tinha feito: trocar cânula de traqueostomia. Tinha que ser rápido e eu fiquei ansiosa."

"..junto com isso, vem aquele receio, o medo de cuidar, ver a incisão e achar que tudo o que você fizer vai prejudicar o paciente, vai doer. Então, você faz o curativo com cuidado, de leve, e não limpa nada! O tempo vai ensinando..."

"Foi o medo do paciente cirúrgico."

"Na enfermaria tem muito caso de CA (câncer) e ai você percebe que são histórias muitas vezes parecidas com as que você tem em casa..."

"Vivenciar uma parada no Centro Cirúrgico..."

"Vencer as expectativas que você cria e a expectativa que as outras pessoas têm de você."

Para o aluno, as questões relacionadas com os ambientes cirúrgicos, as doenças, como o câncer, as situações de emergências, geram estresses sob as quais o aluno tem que eliciar as suas próprias estratégias de enfrentamento, para promover o cuidado com o paciente, mas que são sempre situações com as quais é dificil lidar.

Outro aspecto refere-se a que, no nosso convivio, percebemos que essas dificuldades integram um contexto cultural mais amplo entre os alunos de graduação, ou seja, essas dificuldades fazem parte do nosso mundo, todos sentimo-nos assim.

\subsection{Resultados percebidos quanto à aprendizagem do cuidar}

As percepções dos alunos quanto ao ato de cuidar são completadas nas suas avaliações da aprendizagem.

"O fato de você já ter um pouco de experiência das outras disciplinas, a prática mesmo! $E$ o bloco teórico da cirúrgica ajudou. Foi uma das poucas disciplinas que deu prática."

"Tudo o que a gente aprendeu até agora, ajudou-me, os estágios, as docentes..."

"O fato de você estar cuidando dele em todos os periodos, no pré, trans e pós- operatório. Você tem essa visão geral, como funciona os serviços..."

"A disciplina deu um suporte muito grande para que a gente pudesse encarar a realidade do hospital, do Centro Cirúrgico." 
"A medida que você vai lidando com aquilo, no dia a dia, e a maneira que é ensinada, vai dando... você vai fazendo. Nos últimos dias de estágio você consegue, você pode cuidar dos pacientes."

"O bom relacionamento com os professores."

"Na disciplina, você vai tendo liberdade para estar fazendo aquilo que estudou, estar aplicando. Deu para fazer muita coisa!"

As falas dos alunos apontam aspectos positivos e negativos do processo vivenciado. Destacamos que o relacionamento professor - aluno, no decorrer da disciplina, foi considerado pelos alunos como um dos aspectos mais importantes para a motivação pela disciplina, Por outro lado, como alunos, consideramos que a pouca duração das disciplinas, no curso de graduação em enfermagem, é uma reclamação comum. Outro aspecto a ser destacado é que o momento em que ela é apresentada, na grade curricular, favorece que os alunos aproveitem as suas experiências anteriores, ampliando seus conhecimentos e contribuindo para as suas percepções.

Em toda experiência, a mudança mais significativa ocorre quando consegue-se apreender os seus resultados em toda a sua amplitude:

"...você vê que a cada dia o paciente melhora, ou piora. Deu para perceber quais são as prioridades que são diferentes das prioridades do cuidar de um paciente crônico."

"No começo tinha a necessidade de ter sempre alguém ao meu lado, depois a coisa deslanchou, fiz muito curativo tranqüilamente sozinha... depois fica mais segura."

"... foi muito bom como experiência, mesmo para aplicar daqui para frente, em outras disciplinas e na minha carreira."

"Deu para aplicar todas as técnicas, observar o paciente como um todo..."

"Eu gostei muito porque você atua muito, vai vendo o resultado."

Pelas manifestações dos alunos percebemos que todo o processo vivenciado promoveu mudanças positivas na sua formação, na sua percepção de cuidar e na sua apreensão sobre o paciente cirúrgico.

\section{VENCER A CULTURA DO CUIDAR DO PACIENTE CIRÚRGICO}

As percepções dos alunos quanto ao cuidar do paciente cirúrgico, segundo a nossa interpretação, sintetizam-se no tema Vencer a cultura do cuidar do paciente cirúrgico.

Por esse tema, entendemos que as percepções dos alunos são desenvolvidas a partir das suas dificuldades de conviver com os novos campos de estágios, as novas rotinas, a interação com o paciente cirúrgico. Assim, a dificuldade inicial é de ter uma expectativa de ter em prestar todos os cuidados com o paciente, que se encontra em uma condição de saúde aguda, de maneira eficiente e eficaz, sem lhe causar danos.

Os alunos sentem-se responsáveis por suas ações e, ao mesmo tempo, sentem-se inseguros para desempenhar procedimentos nunca antes realizados, e para identificar as prioridades de cada paciente. A falta de experiência, o conhecimento insuficiente, o medo, a ansiedade são aspectos característicos do profissional em formação identificados falas dos alunos.

Nos relatos, nota-se a cobrança dos alunos quanto ao seu próprio desempenho. Entendemos que essa cobrança é gerada pelo medo e insegurança do aluno de fazer algo que pudesse prejudicar o paciente ou de não realizar corretamente o que aprendeu na teoria, e com isso interferir na sua recuperação.

Foi identificado que a maioria dos alunos consideraram a experiência nova, interessante, devido as aprendizagens que ela possibilita: ter uma visão geral do paciente cirúrgico, ter a oportunidade de acompanhar a evolução do paciente nos momentos pré, trans e pós operatório e avaliar os resultados dos cuidados prestados. Para alguns alunos, a necessidade de ter uma visão geral do paciente cirúrgico foi uma experiência desafiadora devido ao grande número de cuidados a serem realizados, muitos dos quais eles realizaram pela vez.

Conforme as experiências vão ocorrendo, a ansiedade dos alunos diminui e eles relacionam o seu bom desempenho na realização de técnicas devido ao bom relacionamento com o professor. Eles relatam que o embasamento teórico obtido foi paulatinamente sendo colocado em prática, as situações novas foram se tornando familiares, os relacionamentos com o paciente e com a equipe tornaram-se efetivos e, assim, as dificuldades foram sendo removidas.

Segundo os alunos, a disciplina contribuiu significativamente para o crescimento e amadurecimento profissional, favorecendo a aplicação dos conteúdos teóricos aprendidos anteriormente e para transformação do significado de cuidar de um paciente, de alta complexidade, em um paciente cirúrgico.

As percepções obtidas neste estudo são semelhantes aos resultados obtidos no estudo de 
ANGELO (1989), que identificou o significado da aprendizagem prática inicial para a aluna de enfermagem, com o tema "Vivendo uma prova de fogo".

LENARDT (1996), ao relatar a experiência do cuidado cultural na situação cirúrgica, destaca percepções congruentes com as dos informantes deste estudo.

SANTOS (1998), ao buscar compreender a situação cirúrgica sob o ponto de vista do paciente, reconhece que também apresentou muitas das percepções aqui relacionadas.

A experiência de cuidar do paciente cirúrgico, para o aluno do curso de graduação em enfermagem, mostra ser permeada por símbolos e crenças do contexto cultural da enfermagem cirúrgica. Assim, as percepções dos alunos quanto à experiência do cuidar do paciente cirúrgico é um ato de enfrentar e vencer essa cultura.

\section{CONSIDERAÇÕES FINAIS}

Ao realizarmos este estudo tivemos como finalidades inserirmo-nos no desenvolvimento de um estudo sob a abordagem qualitativa e de apreendermos a riqueza das situações vivenciadas por um grupo de alunos que já passaram pela disciplina de Enfermagem Cirúrgica e, portanto, cuidaram do paciente cirúrgico. Frente a isso, o objetivo foi "apreender as percepções do cuidar do paciente cirúrgico atribuídas pelos alunos de graduação em enfermagem". Assim, não pretendemos esgotar o assunto, visto que o estudo envolveu um número limitados de informantes e não foram realizadas observações participantes, que poderiam desvelar outras percepções.

Entretanto, os resultados possibilitaram fazer uma apreensão ampla das percepções dos alunos quanto ao objeto. Vencer a cultura do cuidado de alta complexidade do paciente cirúrgico foi um desafio para os alunos, um desafio valorizado tanto profissionalmente como enquanto pessoa.

$\mathrm{Na}$ literatura de enfermagem, a abordagem, as expectativas e perspectivas dos alunos são pouco abordadas, podendo ser fundamentais para os próprios alunos que, através dos estudos, podem obter uma compreensão das experiências que terão no futuro, controlar suas ansiedades e refletir sobre sua cultura. Estes estudos podem, também, contribuir para mudanças no ensino.

Finalizando, acrescentamos que o processo de pesquisa qualitativa requer intensa reflexão dos pesquisadores, mas contribui para o desenvolvimento do conhecimento ainda pouco revelado, como no presente estudo.

\section{REFERÊNCIAS BIBLIOGRÁFICAS}

ANGELO, M. Vivendo uma prova de fogo: as experiências iniciais da aluna de enfermagem. São Paulo. 1989. 133 p. Tese (Doutorado). Instituto de Psicologia, Universidade de São Paulo.

BLACK, JM.; MATASSARIN-JACOBS, E. Luckmann \& Sorensen: enfermagem médico-cirúrgica - uma abordagem psicofisiológica. 4.ed. Rio Janeiro, Guanabara Koogan, 1996.

GOLDENBERG, S.; BEVILACQUA, RG. Bases da cirurgia. 2.ed. São Paulo, EPU. 1984.

LENARDT, MH. O vivenciar do cuidado cultural na situação cirúrgica, Curitiba. 1996. 146 p. Dissertação (Mestrado). Centro de Ciências da Saúde, Universidade Federal do Paraná.

LUDKE, M.; ANDRE, MEDA. Pesquisa em educação: abordagens qualitativas. São Paulo, EPU. 1986.

SANTOS, SSC. A relação com o paciente cirúrgico: um encontro para a construção de um novo profissional de enfermagem. Ribeirão Preto. 1998. 104 p. Dissertação (Mestrado). Escola de Enfermagem de Ribeirão 'Preto, Universidade de São Paulo.

SMELTZER, SC.; BARE, BG. Brunner \& Suddarth: Tratado de enfermagem médico-cirúrgica. 8.ed. Rio de Janeiro, Guanabara Koogan, 1998.

ZAGO, MMF $O$ ritual de orientação de pacientes pelos enfermeiros cirúrgicos: um estudo etnográfico. Ribeirão Preto. 1994. 154 p. Tese (Doutorado). Escola de Enfermagem de Ríbeirão Preto, Universidade de São Paulo.

\section{Artigo recebido em 12/08/99}

Artigo aprovado em 11104100 